\title{
La interacción dialógica en la comprensión de prácticas autónomas en educación desde Jürgen Habermas*
}

\author{
Julio Cesar Murcia Padilla** \\ Jesús Gonzalo Puín López
}

Recibido: 16 de julio de 2014 - Revisado: 14 de septiembre de 2014 -

Aprobado: 12 de diciembre de 2014

\section{Resumen}

El siguiente trabajo pretende comprender el tránsito que hay entre las prácticas heterónomas y las prácticas autónomas de los docentes, siendo las últimas la base para la consolidación de ambientes éticos desde la interacción dialógica, ambientes que ofrecen elementos favorables para la formación de la autonomía en los estudiantes. Describe el recorrido teórico y documental, relacionado con las condiciones necesarias que ofrece la interacción dialógica desde la postura de la ética del discurso de Jürgen Habermas y otros autores propios de esta línea de la teoría crítica de la sociedad. Luego presenta la fase final del proyecto de investigación del que emerge, esto es, de sus resultados y conclusiones, en términos de orientaciones para acciones y prácticas autónomas docentes desde los principios fundamentales de la teoría de la acción comunicativa, particularmente desde la ética del discurso. En otras palabras, para la generación de prácticas docentes desde la interacción dialógica que propendan por la autonomía sin contradicciones.

Palabras clave: Interacción dialógica, autonomía, heteronomía y ambientes éticos.

Artículo de investigación, resultado del proyecto "La interacción dialógica en la comprensión de prácticas autónomas en educación desde Jürgen Habermas", adelantado en el marco de la Maestría en Educación de la Universidad Santo Tomás, y respecto al cual este artículo se concentra en los resultados y conclusiones.

** Magister en educación de la Universidad Santo Tomás, se desempeña actualmente como docente del Departamento de Humanidades de la misma institución, en el que hace parte del grupo de investigación CETI. Dirección postal: Carrera 9 51-11, Bogotá, Colombia. Correo electrónico: juliomurcia@usantotomas.edu.co

*** Magister en educación de la Universidad Santo Tomás, es docente en la Institución Universitaria Los Libertadores y en la Institución Educativa Distrital "República de México". Dirección Postal: Carrera 16 \# 63 A - 68, Bogotá, Colombia. Correo Electrónico: gonzalopuin@gmail.com. 


\section{Dialogic interaction in understanding autonomous practices in education based on Jürgen Habermas*}

Julio Cesar Murcia Padilla**

Jesús Gonzalo Puín López ${ }^{* * *}$

The present paper aims to understand the movement between heteronomous and autonomous practices of teachers. The latter are the basis for the consolidation of ethical environments from the dialogic interaction (environments that offer favorable elements for the development of autonomy in students). The paper describes theory and literature regarding the conditions offered by the dialogic interaction considered by the discourse ethics of Habermas and other proponents of this line of critical theory of society. It then presents the final phase of the research project of which it emerges, i.e its findings and conclusions, as guidelines for teaching practices and autonomous actions based on the fundamental principles of communicative action theory, particularly from discourse ethics. In other words, for the development of teaching practices from the dialogic interaction, which foster autonomy without contradictions.

Keywords: Dialogic interaction, autonomy, heteronomy and ethical environments.

Research article, a result of the project "dialogic interaction in understanding autonomous practices in education from Jürgen Habermas" advance in the framework of the Master of Education University of Santo Thomas, and for which this article focuses on the results and conclusions.

** Master's in education from the University of St. Thomas, is currently a professor at the Department of Humanities at the same institution, which is part of the research group CETI. Address: Carrera 9 \# 51-11, Bogota, Colombia. Email: juliomurcia@usantotomas.edu.co

*** Master's in education from the University of St. Thomas, teaches at the University Institution Los Libertadores and the District School "Republic of Mexico." Postal Address: Carrera 16 \# 63A - 68, Bogota, Colombia. Email: gonzalopuin@ gmail.com. 


\title{
L'interaction dialogique dans la compréhension des pratiques autonomes en éducation depuis Jürgen Habermas*
}

\author{
Julio Cesar Murcia Padilla** \\ Jesús Gonzalo Puín López**
}

Ce travail cherche à comprendre le passage entre les pratiques hétéronomes et les pratiques autonomes des enseignants, ces dernières étant la base pour la consolidation d'environnements éthiques depuis l'interaction dialogique, environnements qui offrent des éléments favorables pour la formation de l'autonomie auprès des étudiants. Il décrit le trajet théorique et documentaire relié aux conditions nécessaires qui offrent l'interaction dialogique à partir de la position de l'éthique du discours de Jürgen Habermas et d'autres auteurs propres de ce courant de la théorie critique de la société. Ensuite, il présente la phase finale du projet de recherche du quel émerge, de ses résultats et conclusions, en termes d'orientations pour des actions et des pratiques autonomes d'enseignement à partir des principes fondamentaux de la théorie de l'action communicative, particulièrement du point de vue de l'éthique du discours. En d'autres termes, pour la création de pratiques d'enseignement à partir de l'interaction dialogique qui favorise l'autonomie sans contradictions.

Mots clés: Interaction dialogique, autonomie, hétéronomie et environnements étiques.

Article de recherche, à la suite du projet "interaction dialogique dans la compréhension des pratiques autonomes dans l'enseignement de Jürgen Habermas" avance dans le cadre du Master de l'éducation Université de Santo Thomas, et pour laquelle cet article se concentre sur les résultats et les conclusions.

** Maîtrise en éducation de l'Université de Saint-Thomas, est actuellement professeur au Département des sciences humaines à la même institution, qui fait partie du groupe de recherche du CETI. Adresse: Carrera 9 \# 51-11, Bogota, Colombie.Email: juliomurcia@usantotomas.edu.co

*** Enseigne de l'éducation de l'Université de St. Thomas Maître, à l'établissement de l'Université de Los Libertadores et le district scolaire de "République du Mexique." Adresse postale: Carrera 16 \# 63A - 68, Bogota, Colombie. Email: gonzalopuin@gmail.com. 
No hay individuos autónomos sin una sociedad autónoma, y la autonomía de la sociedad requiere una auto-constitución deliberada y reflexiva, que sólo puede ser un logro conjunto de sus miembros... Si el viejo objetivo de la teoría crítica -la emancipación humana- significa algo hoy es la unión de los dos bordes del abismo que se ha abierto entre la realidad del individuo «de iure» a las posibilidades del individuo «de ipso».

\section{Paz Gimeno Lorente}

\section{Del fruto de una investigación}

El trabajo de investigación documental se ocupa del estudio de la interacción dialógica entendida como lente que permite comprender las prácticas docentes autónomas para la generación de ambientes éticos en educación formal. No se desea con ello reducir el amplio campo de reflexión sobre las prácticas docentes a una manera exclusiva de análisis, sino que se busca ofrecer una forma o perspectiva de comprensión desde la teoría crítica de la sociedad, y especialmente, desde la teoría de la acción comunicativa y la ética del discurso. Estos referentes contribuyen a descubrir qué implicaciones posee la interacción dialógica para la comprensión de prácticas pedagógicas autónomas. En otras palabras, se trata de un proceso de descubrimiento hacia prácticas autónomas de los docentes con el fin de generar ambientes éticos que, igualmente, formen la autonomía en los estudiantes y en las instituciones de educación formal.

El itinerario propuesto se despliega en tres capítulos, los cuales buscan desnudar el componente fundamental en cualquier propósito de formación humana: la autonomía de los sujetos para tomar decisiones y con ellas impactar, tanto para su proyecto de vida personal como para con el progreso de la sociedad. Dicha formación humana está a cargo de instituciones o entidades que la misma sociedad en su evolución histórica y social ha generado, como lo son la familia, la escuela y el Estado. Para el caso que compete, la escuela posee un lugar muy especial en la formación de la autonomía de los sujetos.

En el primer capítulo se hace un rastreo histórico de cómo la escuela evidenció prácticas pedagógicas heterónomas, especialmente en las escuelas tradicional y activa y la escuela propuesta por el socialismo de finales de siglos XIX hasta bien entrado el siglo XX. La importancia de este capítulo radica no solamente en mostrar lo que consistieron estas escuelas y sus prácticas pedagógicas en un momento histórico específico, sino en el tipo de sujeto y sociedad que formaron y cómo sus acciones de corte estratégico e instrumental impactaron contundentemente en la construcción del mundo social en el transcurso de la historia hasta nuestros días. Se observa de qué manera las acciones estratégicas e instrumentales de aquellas escuelas configuraron prácticas pedagógicas heterónomas que hoy todavía, de una forma u otra, aparecen en las instituciones de educación formal. En definitiva, lo que busca este primer capítulo es determinar 
las características teórico-conceptuales fundamentales de la heteronomía en las prácticas docentes en educación formal.

En el segundo capítulo se desarrolla la formación de la autonomía desde la ética del discurso como interacción dialógica, tesis central de este trabajo de investigación documental, con el objetivo de establecer las relaciones teóricoconceptuales para la formación de la autonomía desde la ética del discurso como interacción dialógica. La comprensión de los rasgos conceptuales fundamentales de la heteronomía en las prácticas docentes en los tres modelos de escuela citados en el capítulo anterior, sirve como base contextual para poder identificar los elementos constitutivos de la formación de la autonomía dentro de la propuesta de ética procedimental que encarna la ética discursiva desarrollada por Apel y Habermas. Al respecto, se parte de la importancia de dos hechos fundamentales que en el siglo XX impactaron negativamente a la humanidad, con una fuerte tendencia hacia la autodestrucción y un desplazamiento nunca antes visto del lugar del sujeto.

El primer hecho no sólo concibe a la Segunda Guerra Mundial en su tragedia intrínseca y catastrófica, sino que muestra cómo el ser humano fue capaz de llegar a estos extremos, tomando como referencia de análisis el documento de Theodor Adorno titulado La educación después de Auschwitz. El segundo hecho, en el contexto colombiano, es la violencia, pero en términos de una futura educación en "post-conflicto" en Colombia. Lo que busca la evocación de estos dos hechos es la base de la formación de la autonomía: retornar al sujeto.

Aunque la escuela en sus diferentes enfoques, diseños y modelos tuvo como centro la educación de los sujetos, en muchas prácticas pedagógicas el centro no era el sujeto, ni su aprendizaje, ni su autonomía, sino el docente, la enseñanza y la heteronomía. Partir de la idea de retornar al sujeto es partir de la base de su reconocimiento como interlocutor válido; sujeto capaz de generar acuerdos por entendimiento mutuo, gracias a su autonomía y, un sujeto capaz de argumentar sus acciones por medio de la ética del discurso en ambientes de interacción dialógica.

Un sujeto así formado, no será educado en la escuela con acciones estratégicas e instrumentales sino con acciones comunicativas; no será educado con prácticas heterónomas emanadas del sistema o cuyas acciones han sido orientadas por esquemas del sistema, sino formados autónomamente a través de prácticas autónomas; sujetos formados gracias a acciones logradas por la interacción dialógica desde los procedimientos de la ética discursiva.

Por otra parte, el tercer capítulo tiene como objetivo plantear elementos teóricos del diseño de lineamientos generales para la formación de la autonomía desde la interacción dialógica en ambientes de educación formal. Se pretende ofrecer una serie de elementos teóricos que puedan servir como orientaciones epistémicas, éticas, pedagógicas y didácticas para el diseño de lineamientos generales en aras de la formación de la autonomía desde la interacción dialógica, en lo que 
constituye una propuesta osada para que la ética discursiva se viabilice en la educación formal en aras de comprender el mundo de la vida de la ciudadanía.

El énfasis de este artículo, por tanto, se centra en el tercer capítulo de la investigación. Se busca generar una serie de disposiciones que puedan actuar como orientaciones para acciones y prácticas autónomas docentes desde los principios fundamentales de la teoría de la acción comunicativa, pero en esencia, desde la ética del discurso. En otras palabras, lograr generar prácticas docentes desde la interacción dialógica que propendan por la autonomía sin contradicciones.

\section{Del problema}

Las inquietudes que presenta la escuela en la actualidad están relacionadas con el gran número de prácticas heterónomas que en ella se dan y que están relacionadas con los procesos formativos que se generan en su interior. Dichos procesos formativos plantean imaginarios de autonomía, pero en realidad responden a modelos institucionales de organización, los cuales buscan perpetuar prácticas heterónomas en donde la construcción de acciones dialógicas es casi invisible, por no decir que inexistente.

Los sujetos no despliegan sus comportamientos sólo desde su autonomía, sino que están sometidos a fuerzas externas que lo conducen, esto es, fuerzas heterónomas. En términos de Gehlen evocado por Habermas, (...) podemos experimentar cada día este efecto institucional de los instrumentos cuando por las mañanas, en nuestro entorno habitual de trabajo, y con sólo entrar en él, quedamos en el carril de nuestro comportamiento laboral especializado (Habermas, 1975). O mejor:

Cuando un comportamiento convertido en hábito se emancipa de esa manera de sus fines originarios, cuando los instrumentos dirigidos primero a un fin experimentan un vuelco que los autonomiza y cobran una legalidad propia que se convierte en un fin en sí misma, entonces el hombre aprende a "actuar a partir de la institución". Los momentos propulsores se desplazan al objeto e invisten a la institución de contenidos normativos (Habermas, 1975, p. 89).

Al abordar el problema del desarrollo de acciones de interacción dialógica se debe comprender, por tanto, que existe en las instituciones educativas una serie de prácticas heterónomas mediadas por los parámetros de orden institucional, como son las relaciones que se dan entre el estudiante y el docente, en las cuales existe una brecha de autoridad establecida desde el supuesto del rol que cada uno establece en el proceso de búsqueda y adquisición de saberes. Esto ha llevado a que en muchos casos el tema de la construcción de acuerdos en el aula no tenga el suficiente soporte para su consolidación. 
De hecho, lo que busca esta investigación es responder ante la problemática que se genera cuando existe contrariedad o inconsistencia entre la pretensión de formar en la autonomía con prácticas heterónomas de los docentes. O lo que es lo mismo, ¿de qué manera la interacción dialógica permite comprender las prácticas autónomas para la generación de ambientes éticos en educación formal?

\section{La heteronomía en la educación}

De la pedagogía tradicional. Lo que se denomina pedagogía tradicional o su producto concreto, la escuela tradicional, en su variopinto abanico de manifestaciones, a través de cerca de dos milenios, tiene como fundamento esencial, haber girado en torno al profesor y a la enseñanza. Pero no sólo ello marcaría el sello identificador de la escuela tradicional. Por estas razones se considera que las prácticas docentes de la escuela tradicional tienen carácter heterónomo en sus acciones, pues obedecen, siguen y ajustan lineamientos externos. Aún no se ha pensado la pedagogía a sí misma, se piensa en razón de los diferentes modelos que debe seguir.

A la luz de lo anterior, como movimiento crítico que busca cambiar el paradigma educativo tradicional, es decir, cuyo centro sea el aprendizaje y el estudiante y no solamente la enseñanza y el docente, y que, a la vez, sea una pedagogía autónoma, capaz de generar propuestas de perfiles humanos más acordes con la autonomía personal e intelectual, aparece la propuesta de la Escuela Activa o Escuela Nueva que se analizará a continuación.

Con la Escuela Nueva o Activa se logra un gran paso hacia una novedosa manera de comprender la educación tanto en lo macro-curricular como en lo microcurricular, que cubre tanto las acciones de los docentes como las acciones de los estudiantes, se insta para definir, diferenciar y comprender los campos de acción de la didáctica como mediación, no sólo para la fijación de aprendizajes de saberes, sino para la consolidación de la identidad individual, permanentemente confrontada y construida en el trabajo en equipo y del reconocimiento del otro como sujeto con identidad propia al cual debe respetarse.

Estos son elementos muy significativos para el traslado de prácticas pedagógicas heterónomas a autónomas, y por derivación, de sujetos heterónomos a autónomos. Es aquí cuando se logra comprender que de acuerdo a las prácticas de los docentes en su enseñanza y mediación, se posibilita la formación de los sujetos en su aprendizaje autónomo y en su posicionamiento como individualidad que respeta a las demás individualidades, es decir, respeta la autonomía de los otros cuando reconoce la propia. Sin embargo, la Escuela Nueva es producto reaccionario ante la escuela tradicional. Aunque el giro deseado y anhelado de la Escuela Nueva se fundó en la vuelta al sujeto y a su aprendizaje, aún falta incluir las condiciones sociales materiales que enfrentan los sujetos cuando terminan su periodo escolar o universitario. 
Desde otro referente en la historia de la pedagogía, el pensamiento pedagógico socialista marcaría un hito importante en la concepción de escuela, partiendo de la visión del ser humano que necesitaba el momento histórico de ingreso a un nuevo siglo. El siglo XX inicia así su itinerario partiendo del conflicto bélico que vivía Europa y que tendría sus efectos en los demás rincones de la Tierra, especialmente en el sector educativo. Es pertinente, por tanto, concluir este aparte sobre el sueño de ser humano del pensamiento socialista que intenta superar las concepciones antropológicas de la escuela tradicional, cuya marca social es oligárquica, formadora de hombres superiores que pisoteen a los más débiles o vulnerables y que, en consecuencia, responda a un modelo socio-económico ya establecido, pues la escuela en el modelo educativo liberal o burgués, procuraría involucrar a los sujetos formados en ella para apostarle al logro del desarrollo humano desde la perspectiva de la productividad, la competitividad y la industrialización de la sociedad.

La escuela socialista, en cambio, busca otro tipo de marca social que consiste en la apuesta de un único tipo de escuela capaz de formar a los hombres hasta los umbrales de la profesionalización. En otras palabras, articular la formación del pensamiento (aprender a pensar), la adquisición del conocimiento disciplinar (estudiar) que lanzaría al individuo a una acción concreta en la sociedad (profesión), especialmente la dirección y control sobre ésta. Ahora bien, para evitar la división del trabajo a causa de la división del conocimiento en disciplinas (que es lo que ha generado la lucha de clases y, aún más, se ha presentado como la democratización de la escuela, siendo una falsa conciencia educativa) se pretende que cualquier ciudadano, inclusive el obrero o el campesino, pueda acceder al poder $\mathrm{o}$ a ser gobernante.

Sin embargo, en los tres modelos educativos citados, aún la institucionalización del saber solicita de prácticas docentes que actúen en consecuencia con esa misma intencionalidad, por lo que su acción docente se convierte en subsidiaria de un sistema, por ende, no-libre, no autónomo, esto es, prácticas docentes heterónomas.

\section{La formación de la autonomía desde la ética del discurso como interacción dialógica}

Ante la pedagogía tradicional, la Escuela Nueva o Activa y la ideología burguesa dominante de corte cultural, político y económico como las ideas pedagógicas del marxismo y del socialismo, posibilita la apertura de nuevas tendencias, aunque con bases reaccionarias, con una profunda crítica al sistema global o totalizador que las cubre.

Es pertinente entonces determinar qué ideas pedagógicas se elaboran bajo el concepto de crítica en la búsqueda de una escuela que no solamente predique teóricamente la formación de la autodeterminación individual, de la 
independencia personal o en sí de la autonomía, sino que identifique las prácticas docentes realmente autónomas que logren ese fin. Es decir, encontrar los vínculos teórico-prácticos de las acciones autónomas docentes dentro de sus prácticas pedagógicas que viabilicen o generen la ruta formativa hacia la autonomía de los estudiantes.

A partir de este momento, la tesis que guiará las reflexiones subsiguientes que se desarrollará en el transcurso de esta sección será la siguiente: la formación de la autonomía se viabiliza o materializa desde la ética del discurso comprendiéndolo como interacción dialógica. En otras palabras, se responderá parcialmente a la pregunta: ¿de qué manera la interacción dialógica permite comprender las prácticas autónomas para la generación de ambientes éticos en educación formal?

Para el desarrollo de la tesis planteada es imperativo reconocer que toda acción y toda interacción no son dadas por el azar o por la improvisación. Las acciones humanas están motivadas y cargadas de una intencionalidad, de un peso que procura su fin último. El estado actual del mundo, que es fruto de las acciones humanas, no puede contemplarse, comprenderse o interpretarse en sectores o segmentado en campos o lotes demarcados con fronteras políticas, económicas, sociales o culturales. Sólo para describirlo es necesario comprenderlo por regiones, pero en la realidad el mundo de la vida es un sistema complejo de relaciones, de interacciones. Cada acción del pasado, directa o indirectamente, en un lugar o en otro, tiene efectos en el presente, sea de forma inmediata o mediata, pero tiene sus consecuencias (Apel, 1991). Con estas premisas se propende hacer una reflexión crítico-histórica de aquellas interacciones humanas que generaron un tipo de sociedad específica en el siglo $\mathrm{XX}$, en cualquiera de sus cinco continentes, pues con los acontecimientos que ocurrieron finalizando la primera mitad del siglo XX, el mundo ya no sería igual. Lo que se creía que se estaba haciendo bien en la familia, en la escuela, en las instituciones del Estado y en las entidades del sector privado, entra en una profunda crisis de identidad y de prospectiva.

De este modo, la ética discursiva entendida como interacción dialógica será el lente desde el cual se interprete aquel mundo que a partir del fin de la primera mitad del siglo XX entra en crisis (Habermas, 1992). Las interacciones humanas dadas hasta finales de la primera mitad del siglo XX (originadas en el seno de la formación básica en la familia y la escuela bajo el enfoque de la pedagogía aburguesada, ilustrada, enciclopédica y positivista) se fundaron en la transmisión de saberes, en acciones instrumentales o estratégicas, esto es, en acciones heterónomas. Es con la apertura de la crítica sobre la sociedad industrial avanzada o de las propuestas de una teoría crítica de la sociedad cuando se desnuda el trasfondo de las interacciones humanas basadas en acciones de orden teleológico, instrumental o estratégico, siendo en la base acciones heterónomas, esto es, basadas en la dependencia y seguimiento de órdenes, incluso en perjuicio de la dignidad humana. 
Con base en esta tesis, se desarrollará una ruta de comprensión hermenéutica de las propuestas de la Teoría Crítica en sus diferentes despliegues filosóficos y pedagógicos tanto en las formulaciones iniciales como en las elaboraciones o ajustes que le hiciera Jürgen Habermas. Para tal fin, se realizará un recorrido hermenéutico necesario sobre algunos argumentos que fundamentan la tesis planteada.

Es un recorrido necesario, porque en estos elementos que se interpretarán se encuentran las bases para identificar el problema que se engendra cuando de acciones heterónomas se trata, pero a la vez proponer cómo desde la ética del discurso (entendida como interacción dialógica) se fundamentan y se configuran las prácticas docentes autónomas.

\section{Para la comprensión de la autonomía en el contexto de la ética del discurso}

\subsection{La educación después de Auschwitz de Theodor Adorno}

Evocar a Adorno en su conferencia transmitida por la radio de Hesse el 18 de abril de 1966 sobre la educación después de Auschwitz busca no sólo argumentar la tesis que se viene desarrollando, sino arrancar desde un piso contextual que permita comprender la verdadera trascendencia de una formación de la autonomía desde la ética del discurso como interacción dialógica dada desde la educación formal. La no repetición de la experiencia aterradora de Auschwitz no es un mero manifiesto de un filósofo, sino el llamado de atención para que jamás la escuela permita la incubación de las condiciones que generaron tales bárbaros, entre ellas la conciencia de sujeción a las órdenes del otro sin reflexión. Pues cuando un ser humano facilita que su subjetividad, que su individualidad le pertenezca a otro, entrega su libertad, su libre albedrío, su significado y su sentido de realidad. Si la escuela en sus prácticas genera estas condiciones, seguramente no se evidenciarán tales monstruosidades como en Auschwitz, pero sí tiende a generar subterráneamente similitudes camufladas como la corrupción o la permanencia de un conflicto armado como en Colombia, quizás sólo para proteger intereses particulares. Si esto no es Auschwitz en sentido estricto, sí se están incubando lentamente las condiciones que lo generaron.

La escuela debe poner fin a esto. Los docentes no pueden ni deben convertirse en dueños de la subjetividad e individualidad de sus estudiantes; si lo hacen, si se les extirpa su autonomía, se están incubando posibles repeticiones de lo que pasó en Auschwitz. En cualquier lugar del mundo que incube desde la escuela esta barbarie, es posible que se repita lo de Auschwitz: las dictaduras, los totalitarismos de los años setenta y ochenta en América Latina (Chile, Argentina, Brasil, Centroamérica, por citar unos ejemplos) son muestra de ello, al igual que 
democracias débiles en pleno siglo XXI que permiten la permanencia en el poder de sus mandatarios durante decenios bajo la justificación del cumplimiento de un plan de gobierno y peor aún, bajo la manipulación de la conciencia de los que no son ciudadanos plenos sino sólo sufragantes, movidos para votar quizás por el hambre, la pobreza, la falta de techo o el miedo, y no por una opción política autónoma. Si esto desde la escuela no se elimina por un clima discursivo de reconocimiento del otro, estamos ad portas de repetir lo de Auschwitz.

Para el caso colombiano, las situaciones políticas, sociales y económicas complejas a finales del siglo XIX y en especial, la confrontación ideológica de los partidos políticos tradicionales (liberales y conservadores) generaron no solamente discusiones en el orden político en términos de debate ideológico (propio de las democracias) sino que se trasladó al ámbito de la agresión violenta hacia el otro. Fals Borda y su equipo de investigación no sostuvieron sus primeras conclusiones sobre las causas o factores de la violencia en Colombia, por lo que, después de un giro metodológico a su investigación, logran establecer que dicha Violencia (con mayúscula) es un efecto necesario de las acciones apasionadas e irresponsables de los líderes en las regiones, a la vez que eran presionados por los líderes políticos nacionales (o de la capital) de ambos partidos políticos en los primeros treinta años del siglo XX.

Cada extremo político, liberales y conservadores, sólo para proteger y perseverar sus intereses económicos y políticos, excitaron los más bajos y bárbaros instintos de un pueblo con altísimos índices de analfabetismo, por no afirmar un "pueblo ignorante", creando sentimientos de odio y venganza. Ahora bien, en esa misma fracción del siglo XX, aquella fuerza del socialismo que había motivado las diferentes revoluciones en la URSS, causaban gran adhesión ideológica, pero también empatía con los medios utilizados para visibilizar el estado real del pueblo, básicamente, del campesinado colombiano. La excitación de la masa campesina, caracterizada por su apego pasional al color político, no es otra cosa que el mecanismo utilizado como mediación justificadora de la violencia política.

En otras palabras, el abismo político existente entre el pueblo y la clase dirigente elitista y excluyente, o la distancia entre lo rural y lo urbano, o entre el problema de las tierras (desarraigo, desplazamiento y destierro) en el campo y las políticas de centro, generaron las más crueles y nefastas confrontaciones políticas violentas y armadas en los municipios a lo largo y ancho del territorio colombiano. Estas reacciones violentas y armadas del campesinado colombiano generaron la conciencia de un nuevo poder que lograba en algo desestabilizar tanto las fuerzas ideológicas de los partidos políticos como la misma fuerza del Estado en sus instituciones, especialmente, la militar (Borda et.al., 2005).

Siguiendo la propuesta de Adorno, no es en las víctimas en las que recae esta exhortación, sino en los victimarios, los que a través del tiempo convirtieron a la violencia en toda una institución de poder (Adorno, 1966). El campesinado fue utilizado como estrategia instrumental para el logro de sus intereses, el campesino no fue o es el victimario; los verdaderos responsables, siguiendo a 
Adorno, son aquellos que actúan bajo acciones estratégicas instrumentales en aras de satisfacer su telos político e ideológico, que con mecanismos de dominación, excitan los sentimientos más bárbaros y violentos, y con ello, se despojan de cualquier responsabilidad política y judicial.

El punto de convergencia entre los contextos expuestos (Auschwitz - conflicto interno colombiano) es retornar al sujeto. Y es precisamente lo que busca Adorno en su exhortación sobre la educación después de Auschwitz. En el contexto colombiano, podría referirse de la siguiente manera: la educación después del conflicto interno. Y es la educación la responsable. En líneas anteriores se hacía esta misma reflexión en el contexto de Auschwitz, ahora es menester reflexionar en el contexto colombiano. Sólo para transportarse de una imagen a otra, de un contexto a otro, no queda difícil hacer un paralelo entre los registros fotográficos de los campos de concentración de Auschwitz con los secuestrados de la guerrilla encerrados en jaulas de alambres de púas, no queda difícil hacer un paralelo sobre la justificación política del poder del Estado que viabiliza los llamados falsos positivos, sólo para falsamente incrementar el número de bajas del enemigo.

En ambas situaciones, sobre los sujetos-víctimas recaen las acciones estratégicas de índole instrumental: a estos se les despojó de su bien más preciado, su autonomía y por ende, de su libertad. Ahora bien, la tesis indica que la formación de la autonomía requiere de la ética discursiva en el contexto de la racionalidad comunicativa o mejor, dentro de la teoría de la acción comunicativa de Jürgen Habermas, ya que siendo la ética discursiva de corte procedimental, supera las acciones estratégicas o instrumentales por mediación del lenguaje.

\section{1 Ética del Discurso}

El contexto de la ética del discurso es la Teoría Crítica de la sociedad. Ésta se opone a la teoría tradicional, en cuanto se basa por la razón instrumental que implica la positivización del conocimiento de la realidad, por ende, de la realidad misma. En tanto la teoría crítica como nuevo paradigma para la comprensión y transformación de la realidad visibiliza y denuncia el totalitarismo de Estado y la burocratización de las relaciones de todo orden, se caracteriza también por el estudio del autoritarismo que inicia en la familia y la influencia de la comunicación de masas en el comportamiento de los sujetos; por ello, apela a los intereses que se gestan en la interacción comunicativa por medio del lenguaje. Bajo la propuesta de Jürgen Habermas, la Teoría Crítica realiza un giro de tipo lingüístico y comunicativo que abre las perspectivas para una nueva comprensión del entendimiento entre los sujetos desde la racionalidad comunicativa.

El sujeto, entonces, actúa lingüísticamente, en aras de entenderse con los demás, y para ello se establecen algunas pretensiones de validez como la inteligibilidad, la verdad, la veracidad y la rectitud. Así, el entendimiento mutuo busca un acuerdo que logre (dentro de la comprensión que se dé) un saber compartido, 
donde la confianza sea bilateral y por ende, la correspondencia que se despliega entre unos y otros. Un sujeto como interlocutor válido ha de hacerse entender, decir algo, con ingenuidad (autenticidad) y respetando las normas comunicativas vigentes y universales aplicables en cualquier contexto.

De esta manera y bajo las formas de racionalidad de la acción dentro de las cuales se ha configurado la sociedad (teleológica, instrumental y estratégica), Habermas propone la racionalidad comunicativa, fundamento de la ética del discurso en cuanto base del reconocimiento del otro como sujeto validado por su competencia de razón dialógica y por tanto, vehículo para la interacción dialógica entre sujetos libres y autónomos (Habermas, 1992).

Por lo tanto, la ética del discurso e interacción dialógica se fundan en el lenguaje. La razón pura de la comunicación podría desvelarse desde la ética del discurso y la interacción dialógica, a partir del giro lingüístico que desplaza el solipsismo pretendido desde Descartes hasta el enciclopedismo.

La propuesta de la racionalidad comunicativa precisamente se redescubre en aquel giro lingüístico por cuanto que privilegia el lenguaje, pero desde la interacción comunicativa mediante los juegos del lenguaje en la intersubjetividad. Ahora bien, los juegos del lenguaje operan como método que otorga validez y sentido del juego de intenciones que manifiesta la subjetividad sobre el mundo de la vida y opera desde la razón dialógica con el fin de establecer acuerdos o por lo menos, el diseño de consensos sobre aquel mundo de la vida.

Con la razón dialógica enraizada en la ética del discurso, Habermas defiende la urgencia de pulir el discurso filosófico de la modernidad y proponer una racionalidad emancipadora (Habermas, 1975). Se trata de la acción comunicativa como acción social de habla y de diálogo en la que los interlocutores buscan la inteligibilidad, la verdad, la rectitud y la veracidad como en líneas anteriores se exponía y por tanto, la ética del discurso es una ética cognitivista y, a la vez, una ética universalista.

Así, en primer lugar se quiere decir que ha de poder decir cómo se fundamentan los juicios morales y en segundo lugar, que el criterio que da para ello no expresa las intuiciones de una determinada cultura, sino que tiene una validez universal, superando el contextualismo (pragmática universal). De otro lado, es una ética deontológica en tanto que: pone entre paréntesis las cuestiones de la vida buena, limitándose al aspecto de justicia de las normas y formas de acción (justicia social en términos de reconocimiento del otro), y que no mezcla la verdad de un enunciado con la justicia o rectitud de una norma, es decir, da razón de una pretensión universal formal.

El horizonte sugerido por Habermas no instaura alguna situación originaria, al contrario, funda las obligaciones ideales de cómo podría tener lugar el diálogo ético en condiciones reales. De este modo, se da por supuesto que los interesados no quieran dirimir sus conflictos bajo la razón instrumental o mediante la 
fuerza o la violencia ni como un compromiso rapaz para alcanzar un fin, sino fundamentalmente, mediante el entendimiento y la argumentación. Todo esto es una postura por la discusión racional comunicativa.

En términos prácticos desde la teoría de la acción comunicativa, la idea de racionalidad comunicativa se despliega alrededor de la resolución de conflictos o desacuerdos. Pero ello no se apoya en la autoridad, la tradición o la fuerza, sino a través de razones y argumentos que favorezcan o posibiliten dichos acuerdos o consensos. Es por este argumento que el concepto de acción comunicativa alcanza su máxima expresión en tanto que el lenguaje es medio (método) para llegar al entendimiento y a la racionalidad no dominadora en la acción social.

Así, lo que interesa es cómo en la acción social la comunicación interviene como agente que no desnaturaliza (Nietzsche) y que no es dispositivo de sujeción o un mecanismo de control (Foucault); antes bien, que lo emancipe y le realice sin que tenga que diluirse su identidad, autonomía o naturaleza por ninguna razón.

(...) se puede decir que las acciones reguladas por normas, las auto-representaciones expresivas y los actos lingüísticos constatativos, forman en conjunto una praxis comunicativa, que desde el trasfondo de un mundo vital se ocupa de la consecución, del mantenimiento y de la renovación del consenso, de un consenso que descansa en el reconocimiento intersubjetivo de pretensiones criticables de validez. La racionalidad inherente a esta praxis se muestra en que el acuerdo comunicativamente pretendido, en último término, ha de apoyarse en razones (Hernández-Pacheco, 1997).

Es de este modo que en la teoría del lenguaje que maneja Habermas no sólo se ofrece un giro semántico a la comunicación en sí misma, sino que le asigna un centro de gravedad diferente, que es la fuerza ilocutiva, es decir, pragmática del lenguaje. Y con base en esta aseveración, entraría en juego la teoría de la verdad, pues esta estaría dentro de la dimensión pragmática y no racional o epistemológica. Con base en lo anterior, el criterio de este tipo de racionalidad consiste en el éxito técnico de la acción, de manera que la oferta de Habermas se encamina a proponer en la racionalidad comunicativa la comunicación que no asume la verdad como un argumento válido de por sí, sino la pretensión de validez o hipótesis de verdad que entre los sujetos interlocutores se dé. La validación de una verdad ya no es por el éxito técnico de la acción que genera, sino en la aceptación de los interlocutores sobre la misma desde la fuerza del argumento (Murcia, 2009).

En otras palabras, la fuerza del argumento como aprobación de las pretensiones de validez de los sujetos relacionados entre sí por la acción comunicativa, se da desde el reconocimiento del otro en tanto que todo argumento adquiere validez epistemológica sí y sólo sí, mediante la aceptación, o sea, la fuerza de la convicción. Entendiéndose convicción como el acto según el cual un sujeto 
propone a los otros su máxima como objeto de discusión discursiva respecto a su pretensión de universalidad, o sea, no tiene convicción el que está convencido, sino el que convence y encuentra en otros el refrendo de la verdad que propone (Hernández-Pacheco, 1997).

En definitiva, Habermas le apunta a la figura del consenso como ya anteriormente se enunciaba. Consenso que se basa en el reconocimiento del Otro y del acto intersubjetivo entre otros, desde las posiciones de pretensiones de validez criticables (no absolutas) de sus verdades. De este modo, los actores de la acción comunicativa se suponen capaces de críticas recíprocas. No se limita Habermas con el consenso, afirma que para llegar a este todo acto discursivo de relaciones intersubjetivas y recíprocamente criticables debe pasar por el disenso para lograr el anhelado convencimiento.

La razón, entonces, en las ideas habermasianas sobre la comunicación, es el aprendizaje, fruto de un proceso discursivo. Ninguna verdad es absoluta, es criticable y al ser criticable o con pretensiones de validez y/o universalidad, es un contenido transmitido al que se le asigna un proceso de discusión. El aprendizaje, entonces, no es basado desde la teoría tradicional del conocimiento racio-empírico desnaturalizador de la condición humana que critica Nietzsche o un saber que somete, controla y vigila a los sujetos, como afirmaría Foucault, sino que sólo se alcanza el convencimiento de las verdades intersubjetivamente discutidas por los actores de la comunicación cuando por mediación de aquel proceso discursivo las partes del diálogo (criticables mutuamente) alcanzan grados de verdad con validez universal.

Ahora bien, no puede asumirse de manera determinista o fundamentalista que no existe autorreflexión autónoma y libre del sujeto. Todo lo contrario, Habermas asevera que existen convencimientos internos que merecen toda la reflexión íntima, conforme a contrastes con argumentos dados en dicho diálogo, ya asumidos bajo el reconocimiento del otro y de su pretensión de validez del argumento expresado. De allí se sostiene entonces que el proceso de interiorización o internalización del convencimiento es esencialmente de carácter social. Sólo se está convencido de la verdad criticable del otro (Murcia, 2009), es por ello un acuerdo social interiorizado. Sin embargo, se debe hacer algunas preguntas que generan inquietud sobre la propuesta de Habermas y su racionalidad comunicativa. Para ello, se citarán de manera literal como se encuentran en la obra citada de Javier Hernández-Pacheco (1997):

1. ¿No hace resbalar la gnoseología habermasiana hacia un convencionalismo en que, en definitiva, toda verdad depende de su aceptación, y esta de la manipulación retórica?

2. Si la razón es aquello aceptable en el diálogo comunicativo, ¿no hacemos con ello a lo "convenido" principio de la razón? 
3. ¿Qué diferencia hay entonces entre un consenso y un establishment (orden establecido) publicitario?

4. ¿Qué diferencia hay entre discusión razonada y manipulación propagandista? ¿No dependen ambas del mismo éxito, que es convencer a alguien de algo?

Preguntas que inquietan, ya que el convencionalismo aparente de Habermas genera un círculo vicioso entre la convicción o convencimiento causado por la fuerza del argumento y el argumento en sí mismo causado por la convicción. La idea de Habermas es apelar no al argumento con mayor fuerza, no al convencimiento solamente logrado por las criticables posturas de los actores de la comunicación cada cual con su pretensión de validez, sino al ideal de una comunicación libre e igualitaria, desde una lingüística inmunizada contra la represión y la desigualdad (Hernández-Pacheco, 1997).

El consenso se da entonces desde las partes subjetivas con una condición de base, que sean libres e iguales y lingüísticamente competentes para generarlo (el consenso) libre de coerción alguna. Esta es la postura fundamental de Habermas ante el ideal de un consenso dentro de una comunidad dialógica cuya comunicación se base en un sistema lingüístico que no opere desde la desigualdad y desde la opresión o desde formas y mecanismos similares a la no-libertad (Murcia, 2009).

Los partícipes en la argumentación tienen que suponer, en general sobre la base de características formalmente descriptibles, que la estructura de su comunicación excluya toda coerción (ya actúe desde fuera sobre el proceso comunicativo, ya proceda del mismo proceso) que no sea la del mejor argumento (y así de forma que se anule toda motivación distinta de la búsqueda cooperativa de la verdad). Este acuerdo se da entre los hombres libres e iguales, capaces de coordinar sus acciones mediante una comprensión compartida del mundo y de los fines de su acción (Hernández-Pacheco, 1997).

Así, por la racionalidad comunicativa, los sujetos intersubjetivamente relacionados autocritican y abstraen el poder manipulador de las acciones estratégicas o con promesas de éxitos técnicos, donde la interacción simbólica se dé partiendo de los criterios de buena fe, igualdad y libertad de los actores de la comunicación, de la comprensión y entendimiento de las actitudes y símbolos de los sujetos, buscando finalmente el consenso. Los hombres mediatizados por el mundo, se pronuncian, es decir, lo transforman y, transformándolo, lo humanizan, para la humanización de todos. La objetividad de las experiencias consiste en que puedan ser compartidas de forma intersubjetiva, pues estas se presentan con pretensiones de objetividad, y al comunicarlas, al pretender ser válidas, pretenden la verdad (Murcia, 2009). 


\section{Consideraciones para la formación de la autonomía desde la ética del discurso como interacción dialógica}

Sostener la tesis de que la formación de la autonomía se viabiliza o materializa desde la ética del discurso comprendiéndolo como interacción dialógica, logra concebir a la persona con un perfil específico: los sujetos que interactúan desde la racionalidad comunicativa sólo llegan a lograr su grado de desarrollo autónomo desde la socialización que se da al interior de la interacción dialógica; esto quiere decir que el yo se consume como identidad autónoma en la intersubjetividad comunicativamente compartida.

La persona, por tanto, es el conjunto de competencias que convierten a un individuo en un ser capaz de lenguaje y de acción, o mejor, en un ser capaz de tomar parte en procesos de entendimiento a través de la razón dialógica, pues erige una subjetividad identitariamente autónoma como un ser auto-crítico que puede abstraerse de la acción estratégica, instrumental o regulada por finalidades (poder-manipulación) gracias a la racionalidad comunicativa. De hecho, la dimensión dialógica de la razón comunicativa va a estampar significativamente en el sujeto la relación entre la persona, la sociedad y cultura, desde la autonomía desarrollada a partir de la interacción dialógica.

Así, se es sujeto realmente autónomo cuando descubre críticamente las diferentes acciones que se dan en el mundo de la vida, que a la vez que lo confrontan y desarrollan, lo convierten en un sujeto autónomo, racional y comunicativo, esto es, se considera a la persona como un órgano vital de la humanidad, caracterizado por la capacidad de habla y de acción en un encuentro dialógico con los otros sujetos.

En consecuencia con los postulados básicos de la Teoría Crítica reformulada desde la teoría de la acción comunicativa de Habermas, la escuela actual (en su currículo), al responder la pregunta sobre qué tipo de ser humano desea formar, ha de desocultar toda aquella realidad (social, política, ideológica, económica, cultural, religiosa, ética, entre otras) que hace que los sujetos no sean autónomos, sino dirigidos por acciones estratégicas e instrumentales.

Es por ello, que el currículo educativo (macro-currículo) no es sólo un deberser, sino un saber-donde-se-está, y es la comunidad educativa de comunicación (en su discurrir dialógico) la que ha de visibilizar ese saber-donde-se-está. Sólo develando las condiciones desde las cuales se da un tipo de sociedad (caso Auschwitz o caso conflicto interno colombiano), se descubren los mecanismos desde los cuales los seres humanos actúan de una determinada manera. Si se desarrolla en el currículo educativo cada uno de los ítems que enuncia Paz Gimeno (2009), se evidencia la base desde la cual la sociedad se enmarca y por ende, el tipo de escuela que se está gestando. 
En conclusión, el desarrollo de la tesis de este trabajo, esto es, la formación de la autonomía desde la ética del discurso como interacción dialógica, se centra, de manera especial, en el ejercicio concreto de las prácticas autónomas de los docentes. Sólo si son realmente autónomas puede interactuar dialógicamente en aras de la formación de la identidad autónoma de los estudiantes. Los modelos tradicionales de educación y pedagogía mostraron una docencia heterónoma en sus prácticas con el interés de formar la independencia de los estudiantes, de formar su identidad libre y autónoma, situación en sí misma si no contradictoria, sí una antinomia pedagógica evidente. Toda acción y toda interacción no es cosa del azar o de la improvisación, es realizada con una intencionalidad clara.

Con base en lo anterior, entonces, las prácticas docentes, su ejercicio de aula, su intervención intencionalmente pedagógica, sus proyectos transversales, su cotidianidad escolar, sus formas verbales y no verbales de entablar relaciones humanas, laborales, de aprendizaje, de convivencia, en fin, el conjunto de sus acciones, están mediadas por símbolos que no le son ajenos a la comunidad, es más, son creaciones de la colectividad, pues a partir de estos se movilizan desde los más altos objetivos de educación hasta los más concretos ejercicios de convivencia ciudadana. La reflexión que haga el docente de sus propias prácticas se considera el insumo para la revisión y consolidación de los significados que se despliegan en el mundo de la vida escolar, en el ambiente que actuaría como plataforma de condiciones para la formación de la autonomía.

Fundamentalmente, el ambiente ético no es solamente la convivencia basada en el cumplimiento de la norma en términos de acatamiento de deberes y exigencia de derechos, sino la posibilidad de que por medio de la ética discursiva, los sujetos se auto-reconozcan libres y autónomos, capaces de argumentar sus prácticas y las orientaciones que las rigen y a la vez, reconozcan en los otros sus argumentos en aras de la construcción de acuerdos por entendimiento mutuo.

\subsection{Elementos teóricos del diseño de lineamientos generales para la formación de la autonomía desde la interacción dialógica}

En este aparte se desarrolla en su plenitud la tesis citada: la formación de la autonomía se viabiliza o materializa desde la ética del discurso comprendiéndolo como interacción dialógica, especialmente en su segunda parte, esto es, la fundamentación de la ética del discurso como interacción. Ello con el fin de generar los elementos teóricos básicos que posibiliten ser los ejes orientadores para cualquier formación de la autonomía basada en la racionalidad comunicativa.

De este modo, explicitar tanto las condiciones como el ambiente de interacción que genera la conjugación de las mismas en el ejercicio de la docencia en aras de la formación integral de los estudiantes, es una inquietud que no se reduce a un estudio o a una sola investigación, es una indagación permanente de corte 
existencial de aquellos maestros que procuran en susodicha interacción la reiterada formación integral. De manera especial, se hace referencia a los ambientes de interacción en el marco de la formación humana, bajo el presupuesto de que en el trasfondo de toda educación se permea la formación integral, tal y como se prescribe en la Ley de Educación (Congreso de la República, 1994), en la que se cita el pleno desarrollo de la personalidad sin más limitaciones que las que le imponen los derechos de los demás y el orden jurídico, dentro de un proceso de formación integral, física, psíquica, intelectual, moral, espiritual, social, afectiva, ética, cívica y demás valores humanos. Apostarle a una formación integral es apostarle a la generación de ambientes de interacción que posibiliten dicho propósito, porque esta no se puede pretender reducir ni a un enfoque del PEI, ni a un tipo de responsabilidad limitada (a un/a docente, psicólogo/a, coordinador/a), es una inter-acción de todos los intervinientes en el proceso formativo.

Para este ejercicio, entonces, se pretende acuñar el concepto de interacción dialógica que tiene sus bases teóricas en la ética del discurso motivada por Kart-Otto Apel y Jürgen Habermas (Apel, 1991). Este adjetivo de "dialógica" pretende presentar las condiciones de la ética del discurso como plataforma y estructura de la interacción mediada por el diálogo en la educación formal. Es prudente aclarar, de inicio, que la traducción de discurso del contexto idiomático alemán y del contexto filosófico habermasiano, propende significar más discusión, no como se puede connotar en la lengua castellana como discurso u oratoria. Por ello, la interacción dialógica es tal y no discursiva (para evitar incomprensiones) en cuanto que busca más significar la discusión que se da por medio del diálogo, problema este que en líneas posteriores se ampliará.

La interacción dialógica como elemento constitutivo de los ambientes de discusión entre sujetos, especialmente en contextos de formación y educación, se encuadra en el ejercicio del reconocimiento del otro, es decir, y para nuestro caso, la confrontación de subjetividades mediada por la interacción dialógica no es otra cosa que el reconocimiento de un otro yo (alter ego) que pretende ser validado óntica, epistémica, axiológica y dialógicamente, en la participación en deberes, en derechos, en la cultura, entre otros campos, en la puesta en marcha de una ciudadanía que trasciende lo político siéndolo en la misma interacción. De hecho, los ambientes de interacción dialógica han de procurar el ejercicio de la ciudadanía en cuanto expresión de corresponsabilidad hacia el logro tanto de disensos como de consensos gracias al peso de la argumentación de sus pretensiones de verdad y de validez.

Finalmente, este recorrido, en educación formal, ha de procurar siquiera plantear unas líneas aproximadas que diluciden una estrategia pedagógica basada en la ética del discurso para sugerir la creación de condiciones mínimas o fundamentales para ambientes dialógicos que propendan por la interacción comunicativa entre los actores de la escuela tanto en el interior del aula como fuera de ella.

Las condiciones para la ética del discurso, entonces, se estructuran y evidencian desde su fundamentación en la filosofía moral de Kant en cuanto ética cognitiva, 
formal y universal, junto con el aporte apeliano y habermasiano en cuanto que ética procedimental, y en ese último aspecto, la emisión de asentamientos y/o puntos de vista moral subjetivos pero imparciales en relación con un proceso de entendimiento intersubjetivo entre las partes que pretenden acuerdos. Procesos de entendimiento que recurren, interactúan y circulan gracias al ejercicio de emisión de juicios morales imparciales (punto de vista moral), pero que depende de lo que llama Habermas las intuiciones morales que son las que nos informan acerca del mejor modo de comportarnos para contrarrestar mediante la consideración y el respeto la extrema vulnerabilidad de las personas (Habermas, 2000).

Es en este aparte donde Habermas desarrollará las razones por las cuales en la definición de la ética del discurso y en la caracterización de sus condiciones para ser tal cual es, hace énfasis especial en la declaración de juicios morales y de su imparcialidad, pues, para la elaboración de los mismos, mínimamente se necesitan aquellas intuiciones morales. Estas nos dan a conocer cuál es la mejor forma de orientar nuestras acciones para responder de alguna manera a la vulnerabilidad de los demás, a través de la consideración y el respeto. Y es aquí donde aparece una de las tesis que posibilita el vivir y convivir en la comunidad. Cuando se afirma que los demás son vulnerables y que por ello necesitan atención, consideración y respeto, no es otra cosa que asumir que todo ser humano llega a concebirse a sí mismo como sujeto individual y particular sólo dentro de los procesos de socialización e/o interacción social, esto es, que la constitución de la individualidad de los sujetos entendida como la identidad que logra erigir tanto de sí mismo como la identidad para con su inmediato colectivo, se realiza por vía de la interacción con los demás.

Dicha interacción con los otros (socialización) se logra porque los sujetos son capaces de lenguaje y acción compartiendo intersubjetivamente valores, sentidos, significados y contenidos socio-culturales que la misma comunidad de lenguaje posee colectivamente en su mundo de la vida. Es en el mundo de la vida de la comunidad comunicativa donde los sujetos logran protegerse y consolidar los procesos de custodia compartida de la identidad individual y colectiva, generando la orientación de sus acciones por el entendimiento que se logra vía interacción socializadora, donde el lenguaje cotidiano (diálogo) actúa como soporte al proceso de socialización. Queda de más aclarar que es por vía del lenguaje dado en la cotidianidad, es decir, en la interacción dialógica del mundo de la vida, donde los sujetos orientan sus acciones al entendimiento y/o al logro de acuerdos y consensos.

En la medida en que la comunidad se complejiza en estructuras cada vez más diferenciadas y trenzadas de manera heterónoma, los sujetos individuales y particulares se hacen más capaces en su autodeterminación para insertarse, integrarse e interactuar en forma de redes con las diversas dependencias sociales.

Es de este modo como los sujetos al individualizarse vía interacción social mediada por el lenguaje cotidiano (diálogo) se "pierden" en el gran océano de las relaciones densas y multiformes del cada vez más complejo mundo de la 
vida. Es allí, pues, cuando aparece la vulnerabilidad y/o el riesgo de que los sujetos, inmersos en dicho océano, se extrañen a sí mismos. Su identidad viaja en el anonimato de las esferas complejas de relaciones sociales hasta volverse un sujeto perdido, ya no en el océano, sino en el desierto de saberse y concebirse en la paradoja del solitariamente acompañado.

Este es el riesgo de individualizarse vía interacción social. Es por esta razón que la moral, ateniendo esta vulnerabilidad del sujeto identitariamente creado en la comunidad de comunicación, según Habermas, tiene dos tareas importantes: por un lado, valorar y hacer valorar de igual manera a todas las personas de la comunidad por su dignidad que le es connatural, esto es "hacer valer la intangibilidad de los individuos"; y por otro, custodiar las relaciones intersubjetivas de reconocimiento recíproco, pues es este reconocimiento el que crea la individualización de los sujetos dentro de la comunidad, y por ende, su identidad. Así, a los sujetos pertenecientes a un determinado colectivo no solamente los une una historia o una cultura común, sino que dicho reconocimiento los hace uno como identidad colectiva manteniéndolos como miembros intersubjetivamente comunitarios, gestado dicho reconocimiento por la interacción en su mundo de la vida particular.

Por ende, por el mismo hecho de que la identidad del sujeto es una construcción intersubjetivamente elaborada en comunidad por interacción dialógica, su proyecto de vida no es otra cosa que el logro de una cohesión interna de las acciones en el complejo mundo de la vida donde abundan pluralidades de situaciones. Si cada sujeto miembro de una comunidad de comunicación asume los desafíos de las situaciones retadoras del mundo de la vida, esto es, actuando bien, propicia no sólo una eudaimonia particular, sino que por esa intersubjetividad compartida solidariamente en el colectivo, se gesta una eudaimonia comunitaria. Ya Habermas aseveraba que estos macro principios no pueden, no deben disgregarse como si fueran independientes y necesariamente autónomos:
(...) la ética del discurso explica por qué ambos principios provie- nen de una y la misma raíz de la moral, justo de la vulnerabilidad necesitada de compensación que caracteriza a seres que sólo pue- den individuarse por vía de socialización, de suerte que la moral no puede proteger lo uno sin lo otro, no puede proteger los derechos del individuo sin proteger a la vez el bien de la comunidad a que el individuo pertenece (Habermas, 2000).

Así, las dos tareas morales de la ética del discurso: 1) la de la hacer valer por igual la intangibilidad (o su no-cosificación o instrumentalización estratégica) de la dignidad humana para todas las personas, y 2) la del reconocimiento recíprocamente intersubjetivo de las identidades individuales o, lo que es lo mismo, custodiar las relaciones intersubjetivas de reconocimiento recíproco, se enraízan y entretejen por los principios de justicia y solidaridad.

Sin embargo, la ética del discurso exige una condición: que la justicia y la solidaridad no se tomen por separado. Para comprender y fundamentar esta premisa 
habría que retornar a la crítica de Hegel a Kant acerca de su postura universalista abstracta de la justicia, propia de un sistema moral deóntico y formalista de la ética del deber. Inclusive, la crítica de Hegel a los utilitaristas que sosteniendo una ética de los bienes, suponen un sistema moral particularista concreto del bien común o de la solidaridad entendida como la felicidad distribuida (materialmente) a la mayor población posible. Habermas optará por tener en cuenta la crítica de Hegel a Kant, pero con recursos metodológicos del segundo.

Así, para sostener que la justicia y la solidaridad como principios de las tareas morales de la ética del discurso se dan simultánea y articuladamente (y no por separado) en los discursos prácticos entre los sujetos insertos en una comunidad de comunicación mantenida por interacciones dialógicas, toma como punto de partida dichos discursos prácticos e/o interacciones dialógicas. La idea fuerza en este interés por unificar justicia y solidaridad para una ética del discurso en función de sus tareas morales es que las problemáticas y conflictos aparecen en las pretensiones de validez de los intervinientes en las citadas interacciones. Esta es una acción comunicativa que se ha vuelto reflexiva (Habermas, 2000).

Para complementar y ser fieles a las propuestas de Habermas y Apel sobre las condiciones para la ética del discurso se debe hacer referencia a las cualidades propias de los sujetos. Por un lado, los sujetos pretenden el entendimiento logrado por la calidad argumentativa de sus actuaciones y por la custodia irrestricta sobre el conjunto de salvaguardas que los consolidan como colectivo. Es decir, la custodia de los derechos humanos, sobre todo, el de la dignidad humana. De otro lado, los sujetos buscan el reconocimiento de la identidad personal y comunitaria. Este reconocimiento de la identidad no es una manifestación explícita, sino que circula y permea las formas y contenidos de toda interacción intersubjetiva, creando sentidos y significados que los vinculan y los aglutinan. Dicha interacción intersubjetiva emerge gracias al discurso y al concurso dialógico de cada sujeto. Estas cualidades de los sujetos los capacitan para su discursividad dialógica, por lo que es la esencia misma de la ética discursiva.

En definitiva, todo acuerdo, toda resolución de situaciones problemáticas entre sujetos aptos de lenguaje y de acción, solicita la capacidad subjetiva de tomar posición frente a pretensiones de validez susceptibles de crítica, por tanto de libertad individual. En otras palabras, el "sí" o el "no" es cualidad inherente a cada sujeto para participar en discursos intersubjetivamente compartidos.

Una ética del discurso sólo es tal en la medida en que los sujetos tengan la capacidad para ponerse en los zapatos de los demás. Este ejercicio de solidaridad es fundamental para el querer del acuerdo en sí mismo. Es un principio que implica ceder, es decir, estar en la disposición de no solamente escuchar o siquiera comprender al otro, es considerar un alter ego, el yo en el otro y sobre todo, el otro en mi yo. 
En este orden de ideas, la ética del discurso es un conjunto de acciones basadas en la interacción dialógica que se comprenden (dichas acciones) como un proceso de formación de la voluntad colectiva, esto es, que a la vez que cada sujeto se auto-constituye en su propia individualidad y subjetividad (gracias al proceso de socialización), también el colectivo adquiere y desarrolla discursivamente su voluntad comunitaria o de colectividad, capaz de dar razón de la consistencia, conexión y cohesión internas entre las autonomías subjetivas o particulares de cada persona y la inclusión de formas de vida intersubjetivamente compartidas; así, los derechos, las libertades, los deberes, el respeto a la normatividad, los valores, sentidos, significados y contenidos se sostienen gracias a estas relaciones dialógicas interpersonales y del mutuo reconocimiento. Todo ello, pues, garantiza las expectativas de éxito (como lo reitera Habermas) de la ética del discurso si las condiciones anteriormente expuestas se dan en la interacción dialógica (Ruíz, 2008).

Para comprender la realidad desde la cual se pudiese definir la interacción dialógica es necesario tener presente la idea de que la ética del discurso, al ser un proceso de formación de la voluntad colectiva, genera la individualidad o identidad de cada sujeto como construcción social desde, dentro, con y para los otros, en función del mutuo reconocimiento de las subjetividades. Y de otro lado, el colectivo es intersubjetivación de dichas identidades particulares, en donde adquiere el reconocimiento común tanto de la unidad del colectivo como tal, como de las normas, derechos, deberes, valores, sentidos, significados y contenidos desde los cuales interactúan y se construyen.

Allí la ética del discurso actúa tanto por la argumentación de las acciones de los sujetos en colectivo como por la argumentación de los ideales del colectivo en procura de la orientación de las acciones reales en beneficio de todos y cada uno de los miembros. Es esta una interacción dialógica.

La ética discursiva dada en la interacción dialógica posee tareas propias como ética de la corresponsabilidad, a saber: de un lado, la de fundamentar la norma mediante los discursos prácticos; de otro, orientar moralmente la acción por medio del plano normativo fundamentado y susceptible de corrección. Además, en términos educativos, formar moralmente en la consistencia entre fundamentación de la norma y la acción orientada por ella, o entre lo acordado y el respeto de los acuerdos en la práctica.

De hecho, la interacción dialógica que propende la ética discursiva busca generar las condiciones pedagógicas para el desarrollo de la competencia moral comunicativa, que no se reduce al campo formal de la educación, sino que es corresponsabilidad de toda institución donde participen miembros que la conforman como colectividad, pues la institución está conformada por miembros que la integran y por ende, le asignan sentidos y significados. Pero también, la ética discursiva ha de desarrollar la capacidad para cuestionar sobre la naturaleza y el sentido de las distintas interacciones sociales entre los sujetos de dichas instituciones. 
El desarrollo de la competencia moral comunicativa en el ejercicio práctico de la interacción dialógica de la ética discursiva ha de transformarse en una auto exigencia, en una disciplina tal, que siempre oriente los desacuerdos en función del diálogo que los precede, los direcciona y logre solucionarlos por el entendimiento. Diálogo que valide y valore la intervención del otro en cuanto que presente sus razones y justificaciones (punto de vista moral), explicitando las partes del conflicto o del desacuerdo y los puntos álgidos de la disputa. Ahora bien, ello supone el reconocimiento del disenso como posibilidad de progreso y no de retroceso, pues el disenso es evidencia positiva tanto de la realidad de la comunidad como de la oportunidad para mantener un vínculo social con otro yo (alter ego). Es de subrayar que lo que se busca es el consenso como construcción de acuerdos intersubjetivamente compartidos, pero sin satanizar el disenso.

Pero dicho desarrollo de la competencia moral comunicativa en la interacción dialógica no se genera sólo en función de disensos y desacuerdos, es más, no puede entenderse que la interacción dialógica tiene su naturaleza en el disenso, sería reducir su campo de acción. La idea fundamental es que la interacción dialógica que propende la ética del discurso sea un ambiente. Eso significa que toda acción de los sujetos y de los colectivos que conforman se dote de sentido y orientación significativa, donde sus acciones, prácticas y proyectos sean construidas cooperativa y solidariamente de manera intersubjetiva, esto es y en consecuencia, intencionalizar dialógicamente la interacción en la comunidad, validando por el entendimiento de todos la asignación del sentido y significado.

La interacción dialógica, entonces, ha de expandir lo moral en la práctica como procedimiento de argumentación, en cuanto establecimiento de pre-acuerdos, de acuerdos en sí mismos y los compromisos post-acuerdos, ello contribuye a la construcción colectiva de la autonomía individual y por ende, de una comunidad cuyo orden social sea más justo.

Las concepciones que de alguna manera derivan de la política desde el origen de las discusiones griegas como son la democracia, la ciudadanía y la oratoria, ahora hacen parte de la cotidianidad de los Estados y las naciones con sistema de gobierno democrático. Sin embargo, a pesar de todas las elaboraciones filosóficas, políticas, sociales y culturales alrededor del ejercicio de la democracia, hoy parece ser que es un sistema débil, especialmente por el sinnúmero de dificultades que ha presentado como la corrupción, las fugas de poder, la compraventa de conciencias, la crisis de representatividad de los partidos políticos en la corporación legislativa, la pérdida de legitimidad de los gobiernos elegidos popularmente, la debilidad en una moral pública; en fin, la gran lucha y la ilusión que se pretendía desde la Revolución francesa por la preminencia de los derechos del hombre y el ciudadano, se desvanece como el agua entre los dedos. 
Es por ello que ante los diferentes y multiformes acontecimientos del siglo XX y de lo que lleva el siglo XXI se abren diferentes posibilidades para re-alimentar o nutrir la democracia desde posturas más cercanas a la educación ciudadana (también llamada formación ciudadana), a la ética, a la moral pública y sobre todo, al ejercicio real participativo de los ciudadanos. Por la lejanía del pueblo sobre las políticas de Estado, por la confianza en exceso que el pueblo ha depositado en sus gobernantes o representantes, el poder se ha desviado de su camino original. Ahora, los intelectuales que se interesan por la sociedad en términos del sistema de gobierno que las dirige, especialmente la Escuela de Frankfurt en Europa y los diversos movimientos intelectuales y sociales en Latinoamérica, investigan, indagan, estudian y proponen una ciudadanía más amplia, acorde con el estado de cosas actual, capacitada para cubrir otras esferas y otros ámbitos. Estas nuevas posturas sobre la democracia y la ciudadanía, en especial, buscan no sólo fundamentar, sino reorientar y exigir el lugar del ciudadano en las decisiones políticas, aunque, en un ejercicio abarcador, no se reduce a la participación sufragial, sino que alcanza espacios familiares, escolares en todos los niveles de educación, a la cultura, al arte, a la comunicación masiva, en fin, la ciudadanía se está abriendo espacios que antes sólo se referían a la elección de sus representantes políticos.

De este modo, se desea hacer una somera reflexión que aproxime a una ciudadanía ético discursiva, evocando algunas realidades, contextos y propuestas que desde las reflexiones habermasianas en boca de pensadores muy nuestros como Guillermo Hoyos, entre otros, intentan reconceptualizar la ciudadanía desde la ética discursiva o desde la intención de fondo de la teoría de la acción comunicativa.

Es así como la ética discursiva se viabiliza, materializa o se debe comprender en el mundo de la vida de la ciudadanía. De hecho, toda educación en valores (que en esencia redunda, pues la educación está basada en valores) busca formar no sólo la identidad personal de cada estudiante, sino que trasciende en realidades concretas de acción. Acción de los sujetos que no es individual sino colectivizada, esto es, una interacción dialógica en tanto que los sujetos actúan de acuerdo a unos entendimientos logrados gracias al lenguaje, como en líneas anteriores se exponía. Entonces, es necesario evocar a Guillermo Hoyos a la luz de cómo toda formación ética y en valores, debe redundar en la formación de la ciudadanía, a saber:

Las competencias para argumentar, es decir, para dar razones y motivos apostando a las mejores, constituye sin duda alguna el eje del proceso educativo. Hay que destacar cómo en asuntos de ética y moral no sólo siempre es posible, sino que en algunas ocasiones puede ser necesario argumentar. Tal es el caso de ciertas situaciones conflictivas, más fuertes que toda comprensión, que exigen el acuerdo sobre mínimos, y de ciertos programas en el horizonte del bien común, que requieren de acuerdos políticos en el marco de la democracia participativa (Hoyos, 2000). 
La ciudadanía es asumida por los sujetos conforme a la estructura propia de las subjetividades particulares que se dan en el tiempo y en el espacio, volviéndose una práctica que permea las decisiones políticas, pero en poco o en nada, a la conciencia del poder que implica ser ciudadano. Es por esta situación que la idea de ciudadanía cuelga de la idea de construcción de Estado y nación en el marco de un proyecto político, lo que vendría siendo a la luz de la crítica de Jürgen Habermas una acción estratégica o instrumental o, como afirmaría en su momento Michel Foucault, una estrategia de manipulación o de sujeción.

Esta manera de comprender la ciudadanía reduce a los sujetos a un simple instrumento de gestión de las prácticas políticas tradicionales. Son varias las consecuencias de este modelo de ciudadanía heredado del Estado de Bienestar y/o del Estado liberal. Ha generado crisis en el sujeto ciudadano en cuanto que al ser alienado por este mecanismo ritualista, pierde su capacidad de libre decisión, de creación de otros escenarios de participación o de inventiva de esferas diferentes de transformación social y cultural desde su ser ciudadano. La crisis de institucionalidad, la intolerancia, el irrespeto a la diferencia, la corrupción, la deslegitimación de normativas con vicios de toda índole, la fuga de poderes, etc., son evidencia de la crisis de la ciudadanía desde este enfoque tradicional de la misma.

El contexto anterior trata de ubicar la realidad y el concepto de la ciudadanía que se ha generado por la tradicional visión del ser ciudadano sólo en términos de su participación electoral. Sin embargo, en el ejercicio de formación de la ciudadanía, de la pretensión de descubrir una nueva manera de hacer ciudadanos y de ser ciudadanos, la responsable directa de este ejercicio es la escuela en todos sus niveles. Ya en su momento, Guillermo Hoyos Vásquez hace un análisis en la investigación sobre la "formación ética, valores y democracia" (Hoyos, 2000), destacando en primer lugar que, aunque la Escuela y los maestros no son los únicos responsables de una educación ciudadana con nota inferior a "aprobado", sí tienen en sus haberes relacionar la educación y el ejercicio de la ciudadanía como tal. Así, la escuela ha de esforzarse por la formación para la convivencia ciudadana en aras de la paz tanto como fin inmediato como ordenamiento político de urgente necesidad, por encima de proyectos políticos partidistas con otros intereses. Una formación que propenda llegar a acuerdos y entendimientos que se logren por medio de la convicción ofrecida en la interacción dialógica y no por las vías de hecho, y eso tiene que verse reflejado en las dinámicas internas en las relaciones internalizadas de toda comunidad educativa en los niveles de preescolar, primaria, secundaria, media y superior, formal y no formal.

La formación cimentada sobre la generación de acuerdos y entendimientos en medio de los conflictos presentados en la escuela debe propender el manejo de la ciudadanía desde la interacción y mediación de la comunicación. Según el citado autor (Hoyos, 2000), el primer momento de la comunicación es el nivel hermenéutico, es decir, la comprensión de sentido de todo tipo de expresiones, que a la base no es otra cosa que el reconocimiento del otro, del derecho a la 
diferencia, de la perspectiva de las opiniones personales y de cada punto de vista moral en una interacción de subjetividades o lo que es lo mismo, en la intersubjetividad, esto es, el logro del entendimiento a la vez que cada sujeto con pretensiones de objetividad y verdad reconoce en el otro, también, dichas pretensiones. El principio puente (en el contexto de los acuerdos y entendimientos) en el sistema moral comunitarista es la comunidad, la tradición y el contexto socio-cultural, pues dicho principio ha de ser transformador valorativo en cuanto que es el sentido de identidad y pertenencia a una comunidad.

Así, los conflictos exigen acuerdos y entendimientos en cuanto que son conflictos en razón de la diversidad de interacciones de sentidos globales de vida, de historia, de concepciones omnicomprensivas, de corte religioso, moral y filosófico. Ahora bien, dicha diversidad y su interacción en la comunidad sólo es asumida bajo un pluralismo razonable, es decir, cuando se generan intentos de consensos alrededor de principios básicos de justicia manifiestos en la igualdad de libertades y oportunidades y en la distribución equitativa de bienes primarios. Ello presenta sus dificultades de rigor natural, como por ejemplo que en aras de llegar a un consenso por medio de la comunicación puesta al servicio de los conflictos, sólo se llega a entendimientos de la mayoría, negando el legítimo derecho de disenso de las minorías. Por ello, los acuerdos han de ser establecidos sobre unos mínimos consensuales que son los derechos humanos. Y es allí donde aparece el concepto de ciudadanía política y ciudadanía cultural, puesto que se logra llegar a la convivencia y al respeto del otro como tal y de sus pretensiones, en medio de la interacción de las diversidades pluriculturales de los sujetos intervinientes.

En definitiva, aquel principio puente, es decir, el principio de identidad y pertenencia a la comunidad que actúa como principio transformador valorativo, solicita la comunicación como eje para la convivencia ciudadana entre la diversidad. Dicha comunicación fundamentalmente se despliega en dos grandes condiciones, la primera como uso informador del lenguaje y la otra, como orientación para la solución de conflictos. El uso informador del lenguaje interactúa en función de la comprensión de sentido, sentido que es contextualizador para que se valide la necesidad de ver al otro como válido en la interacción de sus manifestaciones culturales y por tanto, su reconocimiento como diferente y diverso, ello para intentar darle el poder a la comunicación como fuerza de argumentación. Ahora bien, la comunicación como orientación a la solución de conflictos se convierte en mediación para el logro de consensos desde unos acuerdos basados en unos mínimos inalienables, los derechos humanos; así, la comunicación desde el diálogo con pretensión de consenso buscará lo correcto, lo justo, lo equitativo por medio de la fuerza de la argumentación, convirtiendo a los sujetos sociales, no sólo en sujetos políticos y ciudadanos, sino en sujetos discursivos hacia la argumentación, donde toda actividad moral entre estos es argumentativa. 


\section{Conclusiones}

\subsection{El reto por la formación de la autonomía}

La decisión de tomar como punto de partida la pregunta que motivó este estudio, es decir, ¿de qué manera la interacción dialógica permite comprender las prácticas docentes autónomas para la generación de ambientes éticos en educación formal? tiene unas motivaciones pedagógicas y experienciales especiales. Durante todo el proceso que se llevó a cabo para responder a esta pregunta se realizó indagación bibliográfica, confrontación con la práctica docente e interpretación de realidades emergentes. No obstante, en esencia lo que marcó un valor agregado fue la evocación permanente de la propia práctica pedagógica de los autores de este trabajo.

Una de las grandes debilidades del colectivo maestro, en medio del agitado mundo de la docencia, de los tiempos reducidos para meditar su práctica y por ello, de su poca reflexión tendiente a transformar e innovar con nuevos marcos u orientaciones de acción, es la ausencia, precisamente, de un soporte teórico que dé luces para transformar o fortalecer sus acciones pedagógicas.

Este agitado mundo de la docencia ha convertido al maestro en un hacedor de tareas, en aquel que debe cumplir con unos lineamientos educativos internacionales, nacionales, regionales y locales, quedando a la distancia el verdadero impacto en la vida de los estudiantes. En otras palabras, las prácticas docentes de los maestros se han convertido en acciones basadas en la heteronomía y por ende, esta actuación se refleja en la formación que reciben los estudiantes, también heterónoma y por tanto, hacedora de sujetos heterónomos. Lo que se buscaba con esta investigación era comprender si existía una relación causal o directa entre las prácticas docentes heterónomas de los docentes con la formación de la autonomía de los estudiantes. Escudriñando en la historia de la educación y de la pedagogía se encontró que esa relación causal o directa existió y perduró por milenios, inclusive en la actualidad, con sus características, sus contextos y sus ambientes, pero a la base, las prácticas docentes de la llamada escuela o pedagogía tradicional fomentaron este vínculo causal entre prácticas pedagógicas heterónomas de los docentes y la heteronomía personal de los sujetos que pretendían formar como independientes.

El recorrido realizado, entonces, llevó a concluir que dichas prácticas pedagógicas heterónomas formaban sujetos heterónomos, pero con la contradicción de educar en la libertad, en la autodeterminación, en la independencia. En los diferentes momentos históricos, siempre se pretendió esta iniciativa en las escuelas, formar la voluntad y la conciencia, pero sus prácticas educativas desdecían este ideal.

El mismo itinerario de la historia, sus acontecimientos, los grandes fracasos de las revoluciones y los ideales de libertad, justicia y autonomía de los pueblos, 
a la vez que de la liberalización de la academia, entre otras tantas realidades, solamente lograron la entrada a una sociedad en crisis en el siglo $X X$, de un mundo científica y tecnológicamente avanzado, pero con la humanidad ensangrentada, dividida, intolerante y peligrosamente, en el filo del abismo hacia su exterminio. Y lastimosamente la escuela tiene mucho que responder ante estas realidades.

La indagación realizada mostró cómo la escuela en su afán de formar sujetos de excelencia, formó sujetos incapaces de autodeterminarse verdaderamente y de convivir con los otros. Los intentos de la escuela tradicional de reorientar sus prácticas centradas en la enseñanza y en la docencia, las reacciones de la Escuela Nueva por recomponer la sociedad reconstruyendo la escuela, centrándola en el aprendizaje y en el estudiante, y la propuesta del pensamiento pedagógico socialista de fundar una escuela única que no generara desde sus acciones educativas prácticas de exclusión como las evidenciadas en la escuela burguesa, no tuvieron el éxito esperado. Ello condujo a pensar la escuela y la pedagogía, pero las prácticas de poder, de autoritarismo, de exclusión y de dominio, seguían siendo visibles en los ambientes internos de las escuelas.

Por tanto, el recorrido evidenciado en este estudio mostró contundentemente cuáles son las características teórico-conceptuales fundamentales de la heteronomía en las prácticas docentes en educación formal y sobre todo, cómo constituyeron un tipo específico de ser humano y de sociedad. Un ser humano que en discursos pedagógicos se pretendía formar en y para la autonomía, pero en las prácticas docentes concretas, del día a día, seguía existiendo la distancia irreconciliable entre dos sujetos: el docente y el estudiante, que inclusive comparten más tiempo que entre padres e hijos.

Lo anterior marcaría el horizonte para establecer las relaciones teóricoconceptuales para la formación de la autonomía desde la ética del discurso como interacción dialógica. Aquel recorrido realizado llevó a reflexionar sobre el lugar de una nueva concepción de escuela con el riesgo inminente de ser osados en esta pretensión, pero ser esperanzadores en que sí es posible soñar una escuela diferente, aquella que contemple unas nuevas y diferentes relaciones entre los actores de la escuela. El estudio llevó a caracterizar este ideal de formación de la autonomía desde la implementación de la ética del discurso diseñada por Apel y trabajada por Habermas en su teoría de la acción comunicativa. Una verdadera formación de la autonomía, siendo parte fundamental de la personalidad e identidad de los estudiantes, debe darse en el plano de la comunicación, pero de un tipo específico de comunicación, y se eligió la lograda por la razón dialógica por mediación de los presupuestos epistémicos de la ética del discurso.

Así, comprender la ética del discurso como interacción dialógica (razón comunicativa) prevé sujetos capaces de auto-determinarse, de validarse a sí mismos como interlocutores en medio de un mundo fatigado por acciones heterónomas tendientes a la destrucción o al conflicto intencional. Permite ser 
un sujeto dialógico que, desarrollando su autonomía, pueda ejercerla como poder justificatorio de su actuar, esto es, por un lado, tener principios formales que orientan su acción, y por otro lado, poseer herramientas procedimentales que propendan por la consolidación de un proyecto de vida autónomo basado en el reconocimiento del otro como interlocutor válido, y por ende, construir un mundo basado en argumentos y en creaciones intersubjetivas fundadas en el logro de acuerdos por entendimiento mutuo.

La escuela, entonces, como lo es la familia o la empresa, ha de convertirse en el lugar propicio cuyo clima desarrolle esta formación de la autonomía desde la lógica procedimental de la ética del discurso entendida como interacción dialógica. Todo lugar donde habita el ser humano y en donde se desarrolla como sujeto dialógico, necesita de un ambiente que logre desplegar las condiciones para que esta iniciativa pueda realizarse a plenitud.

Lo hallado y construido, configuró la plataforma epistémica desde la cual sugerir unos elementos teóricos del diseño de lineamientos generales para la formación de la autonomía desde la interacción dialógica en ambientes de educación formal. Las investigaciones realizadas en torno a este planteamiento son bastantes, diversas y enriquecedoras y sobre estas se apoya este estudio, pues no puede desconocerse el trabajo realizado y sobre todo, ignorar la búsqueda de una escuela cuyo ambiente propicie la formación de la tan citada autonomía desde un enfoque específico, y para el caso de esta investigación, desde la ética discursiva.

La pretensión final de esta investigación, más allá de proponer fórmulas, recetas, manuales o guías para la convivencia, se centra, precisamente en la Escuela, en todo lo ancho y largo de este término. Para el mundo de la docencia y de las prácticas docentes se han diseñado tantos manuales o guías didácticas como estilos docentes existen, por ello, se expone una serie de elementos que buscan ser, como escribiría Habermas, unos principios orientadores que logren crear pautas para el aterrizaje de la tan nombrada formación integral o lo que es lo mismo, la formación de la autonomía.

Pensar sobre estos elementos teóricos hizo introducirse necesariamente en campos tan complejos como lo son los ambientes éticos de las instituciones educativas, la búsqueda de la formación de la ciudadanía y hasta la formación del pensamiento crítico, y seguramente, otros tantos más elementos que bien pueden ser motivo de un trabajo de tesis doctoral, debido a la situación histórica en la que se encuentra Colombia con ruidos muy optimistas [o no] sobre el fin del conflicto, precisamente, en los diálogos que se llevan a cabo entre las FARC y el Gobierno colombiano en La Habana, Cuba.

Bajo este horizonte en el que se despierta esta patria todos los días, se piensa esta propuesta. Lo que se logró comprender es indiscutiblemente el ideal de ciudadanía que tanto necesita esta patria. Por ello, es de vital importancia para la escuela colombiana lograr establecer pautas de entendimiento mutuo desde 
la razón dialógica, con lo cual no solamente se logra una escuela con ambientes éticos óptimos para el desarrollo de la autonomía, sino sujetos capaces de responder como ciudadanos autónomos ante las nuevas noticias de un país en post-conflicto.

\subsection{El reto de soñar una nueva escuela desde una nueva pedagogía}

Como en líneas anteriores se exponía, escudriñar la historia de la educación y de la pedagogía con unos lentes específicos colaboró en mucho en la comprensión del fenómeno social llamado escuela.

Pensar en los aportes de esta investigación en pedagogía, realmente es un reto. Haber leído la escuela desde la heteronomía y la autonomía abrió un horizonte nuevo sobre el estado en el que se encuentra el actual orden mundial. Es sobre este aspecto que recae toda la fuerza de cualquier iniciativa de modificación de la escuela, pues los hombres y las mujeres del Tercer Milenio necesitan una clara orientación para la configuración de su proyecto de vida integral, en tanto son los estudiantes en cualquier nivel de educación los que necesitan una nueva estructura educativa para la formación de su autonomía.

El presente estudio pone ante los docentes un espejo, no solamente donde se refleja su imagen como responsable de la educación de sus estudiantes, sino como retrovisor, en el que se proyecta el pasado de la escuela y cómo ese pasado aún es vigente en aquel docente que se ve a sí mismo en el espejo. Es el llamado entonces a que la docencia reflexione sobre sus prácticas heterónomas, esto es, aquellas rutinas repetidas hora a hora, día a día, semana tras semana y año tras año en las aulas de clase. Pero igualmente, para las instituciones de educación en sus diferentes niveles, pues son ellas las encargadas de direccionar las posibilidades políticas de apertura hacia un ambiente ético consecuente con la pretendida formación de la autonomía.

De otro lado, aterrizar en la pedagogía los principales fundamentos de las elaboraciones de la Escuela de Frankfurt, especialmente en el campo educativo, es todavía un reto, que en los últimos años ha tenido gran acogida, sobre todo en aras de seguir nutriendo la pedagogía social y crítica de Freire, la pedagogía crítica de Foucault, la misma Teoría Crítica o las propuestas de MacLaren. Sin embargo, está latente el riesgo histórico de seguir creando propuestas novedosas con prácticas tradicionales o heterónomas, de seguir inventando teorías pedagógicas, pero con limitadas didácticas y ambientes inconsecuentes, si no contradictorios.

Este estudio, en definitiva, propende para que se piense la pedagogía, pero fundamentalmente se reflexione desde su componente dialógico y ético; desde una postura abierta de diálogo bajo los fundamentos de la ética del discurso, puede realmente el estudiante ser el centro junto con el aprendizaje de la educación, 
y a la vez, que sea la formación de la autonomía ciudadana el punto de llegada para el cual se debe trabajar desde los primeros niveles de educación hasta el último, si es que existe.

\subsection{El reto de continuar construyendo sujetos basados en la interacción dialógica o razón dialógica en tiempos de post-conflicto}

Finalmente, después de diversos tropiezos, este estudio tiene como bondad especial la oportunidad de generar más y nuevas expectativas a futuro, sea en el campo de formación docente, sea en el campo práctico en educación como tal.

Este estudio abrió más preguntas al respecto de la formación de la autonomía y de la pretensión de validar la ética discursiva como procedimiento para su implementación en la escuela del siglo XXI en Colombia, especialmente ante la entrada de un nuevo amanecer en esta patria, como lo es el post-conflicto.

El siglo XX y lo que ha corrido del siglo XXI en Colombia fue leído, estudiado e investigado bajo la fuerza del conflicto interno armado. Los jardines, los colegios y las universidades educaron a sus estudiantes desde la mirada gris por el desdén de una esperanza abortada y de un horizonte rojo por la sangre de quienes luchan por ideales, sean del Estado, sean de la insurgencia armada. Es tiempo de cambiar esa fuerza y ahora, leer a Colombia con la esperanza de la fuerza del post-conflicto, y aquí la escuela tiene mucho que hacer.

El reto, pues, es formar la autonomía desde la interacción dialógica en tiempos de transición, de cómo educar, de re-educar a los excombatientes, de qué tipo de formación debe tener la fuerza pública ya no desde la perspectiva de la guerra de guerrilla, sino de la convivencia donde las armas no sean las que escriban con su plomo la historia, sino donde los lápices y las sonrisas de los niños realmente sean de esperanza y no de engaño.

El reto es cómo devolver la esperanza desde el ambiente escolar y universitario, a través, no solamente del estudio riguroso (que es necesario) sino desde la apuesta por la generación de acuerdos por entendimiento mutuo, donde el procedimiento sea desde la ética del discurso, que en definitiva no es más que el reconocimiento del argumento de otro y de cómo generar conciliaciones entre los argumentos más fuertes. Al fin y al cabo, eso es ciudadanía, convivir bajo el respeto de los derechos, de los deberes y de la verdadera participación democrática. 


\section{Referencias}

Adorno, T. W. (1966). La educación después de Auschwitz. (Conferencia transmitida por Radio de Hesse el 18 de abril de 1966). En: Zum Bildungsbegriff des Gegenwart, Francfurt, 1967, pp. 111 ss.

Appiah, K. A. (2007). La ética de la identidad. Buenos Aires: Katz Editores.

Blanchard, M., \& Muzás, M. (2006). Propuestas metodológicas para profesores reflexivos. Madrid: Narcea.

Cortina, A. (2007). Ética De La Razón Cordial: Educar En La Ciudadanía. Oviedo: El Siglo XXI.

Cousinet, R. (1959). Un nuevo método de trabajo libre por grupo. Buenos Aires: Losada.

García. M. (1996). La Filosofía de Kant. Una Introducción a la filosofía. Barcelona: Ediciones Cristiandad: Antropos.

Gimeno Lorente, P. (2009). Didáctica Crítica y comunicación, Barcelona: Octaedro.

Godotti, M. (1998). Historia de las ideas pedagógicas. Buenos Aires: Siglo XXI.

Habermas, J. (2000, 11 de junio). Aclaraciones a la ética del discurso. Recuperado en: http://pendientedemigracion.ucm.es/info/eurotheo/habermas.htm

Habermas, J. (1992). Teoría de la Acción Comunicativa I. Buenos Aires: Taurus.

Habermas, J. (1992). Teoría de la Acción Comunicativa I: Racionalidad de la acción y racionalización social. Buenos Aires: Taurus.

Habermas, J. (1992). Teoría de la Acción Comunicativa II. Buenos Aires: Taurus.

Hernandez-Pacheco, J. (1997). Corrientes filosóficas (II) Filosofía Social. Madrid: Tecnos.

Jongitud, J. (11 de junio de 2013). Teorías éticas contemporáneas. Recuperado de http://www.seminariodefilosofiadelderecho.com/docencia1/humanos/ CONTENIDOS/DDHH/teorias\%20eticas\%20contempor\%C3\%A1neas.htm

Lapresta, C. y Huguet. Á. (2006). Identidad colectiva y lengua en contextos pluriculturales y plurilingües. Revista Internacional de Sociología (RIS), LXIV(45), 83-115.

Larrea, J. (1960). La educación nueva. Quito: Casa de la Cultura Ecuatoriana. 
Lertora M., C. (2010). Dos modos del método escolástico en Tomás de Aquino (Vol. 17). Revista Española de Filosofía Medieval 17, 93-101. Recuperado de http:// dialnet.unirioja.es/servlet/articulo?codigo $=3425649$.

María, M. G. (2009). Los estudiantes, su percepción sobre lo que implica "ser estudiantes" y "hacer universidad". Revista de Investigación Educativa, 27(1), 9-26.

Martinez, M. (2006). Formación para la Ciudadania y Educación Superior. Revista Iberoamericana de Educación, 42, 85-102.

Murcia, P. P. (2009). La práctica pedagógica en el aula. Un análisis crítico. Revista Educación y Pedagogía, 4, 73-92. Recuperado de: http://aprendeenlinea.udea. edu.co/revistas/index.php/revistaeyp/article/viewFile/5624/5045.

Nietzsche, F. (1993). Humano, demasiado humano. Madrid: M.E. EDITORES, S.L.

Radl Philipp, R. (1998). La teoría del actuar comunicativo de Jürgen Habermas: un marco para el análisis de las condiciones socializadoras en las sociedades modernas, Papers, 56, 103-123, recuperado en: http://www.infoamerica.org/documentos_pdf/habermas02.pdf

Reale, G. (2009). Historia de la filosofía. (Vol. 6. De Nietzsche a la escuela de Frankfurt). Bogotá: UPN - San Pablo.

Ruiz. A. (2008). El diálogo que somos. Ética discursiva y Educación. Bogotá: Magisterio.

Siurana, J. C. (1999). La evolución del pensamiento de Karl-Otto Apel frente al problema de la reflexión. Anthropos, 183, 100-105. Recuperado en: http:// www.uv.es/gibuv/ApelReflexionSiurana.pdf

Suarez, G. (2013). Generación de Ambientes Éticos en la Escuela (proyecto de investigación). Bogotá: USTA. Recuperado en http://201.234.78.173:8081/cvlac/ visualizador/generarCurriculoCv.do?cod_rh=0000145491 